\title{
La jurisprudencia de las Cortes constitucionales europeas sobre el derecho de las personas y de la familia*
}

\section{Case-law of the European Constitutional Courts on the rights of an individual and on family law}

\author{
LAURENCE BURGORGUE-LARSEN*** \\ Laurence.Burgorgue-Larsen@univ-paris 1.fr
}

\section{RESUMEN}

En este artículo se presenta la evolución de los tribunales europeos a propósito de los derechos fundamentales de las personas que, dada su fragilidad, han sido más discriminadas, y cómo a través de decisiones de justicia constitucional los jueces, basados en un activismo innovador, los han protegido y garantizado tomando como eje la dignidad humana, en tanto principio y derecho que prácticamente permite abordar cualquier situación, como se puede apreciar en decisiones que desarrollan la igualdad a propósito de familia, uniones homosexuales, situación de inmigrantes, entre otros.

PALABRAS CLAVES: derechos fundamentales, dignidad humana, derechos de los individuos, ley de familia.

\section{ABSTRACT}

This article presents the evolution of European courts regarding the fundamental rights of the individuals who have been discriminated due to their condition of vulnerability and an account of how the judges have protected them through decisions of constitutional justice focusing on innovative activism. The judges have also granted those rights basing on human dignity as the right and principle that makes it possible to address any situation; such fact can be evidenced in the decisions that develop equality on the issues of family, same-sex unions and immigration situations.

KEYWORDS: fundamental rights, human dignity, rights of the individuals, family law.

Fecha de recepción: marzo 20 de 2013

Fecha de aceptación: abril 23 de 2013

* Artículo de reflexión producto del informe final de investigación que sobre tribunales europeos en materia de derechos humanos adelanta la autora. La traducción al español que publicamos en este número es original e inédita previa autorización y revisión por la autora.

** Docente en la Escuela de Derecho de la Sorbonne (Universidad Paris 1), Instituto de Investigación en Derecho Internacional y Europeo (IREDIES). 


\section{Introducción}

Metamorfosis de civilizaciones. Así podríamos sintetizar la profunda mutación que ha conocido desde hace aproximadamente veinte años el derecho de la familia y el estado de las personas en Europa. Este derecho que había sido construido sobre la legitimidad de las desigualdades y su correlativa institucionalización se verá transformado por la corriente igualitaria y liberal imbuida por la filosofía de los derechos humanos. Las desigualdades fundadoras del derecho de la familia desaparecen; legisladores y jueces nacionales son influidos -por no decir obligados- por las dinámicas armonizadoras del derecho internacional y europeo de los derechos humanos. Sea deplorada o alabada, la metamorfosis es unánimemente reconocida. El asunto es explosivo pues se trata de una verdadera "cuestión de civilización”, que acaba con toda una concepción de la familia ${ }^{1}$ para instaurar una nueva era, aquella del individualismo y el pluralismo. ${ }^{2}$

A la concepción holística del derecho de la familia, en la que el grupo ganaba sobre el individuo y la figura del pater familias estructuraba -jerarqui- zando- la célula familiar, le sucede la primacía del individuo. Pasamos "del sentimiento del nosotros", de la comunidad familiar al "sentimiento del yo como individuo libre y solitario". ${ }^{3}$ Los intereses de la persona, de todas las personas -mujeres y niños incluidos- terminaron por ser considerados. La igualdad de los sexos remodeló radicalmente las relaciones entre hombres y mujeres, mientras que la igualdad de las personas conllevó la toma en consideración del niño, que pasó de ser un objeto de protección a un sujeto de derechos. Los principios consagrados en la Convención de Nueva York de 1989, inspirados por la jurisprudencia de la Corte Europea, han sido los principales factores de esta transfiguración.

Pasamos de la sacralización de un modelo familiar único, fundamentado en la familia legítima, cuyo objetivo era asegurar la estabilidad del cuerpo social por la transmisión del patrimonio, a la valorización de otras estructuras familiares, en particular la familia natural. Estableciendo la igualdad entre familias legítimas y naturales, los legisladores cesaron de privilegiar el matrimonio como modelo de organización de la vida familiar y de imponer un modelo familiar único. ${ }^{4} \mathrm{El}$ "plu-

1. F. Dekeuwer-Défossez, «Conclusions», in F. Sudre (dir.), Le droit au respect de la vie familiale au sens de la Convention européenne des droits de l'homme, Bruxelles, Bruylant, 2002, p. 400.

2. Droits européens et droit de la famille. Contribution à l'étude de la dynamique du rapprochement, Thèse, Université de Bourgogne, 2011 , passim.

3. M.-T. Meulders-Klein, «Individualisme et communautarisme: l'individu, la famille et l'État en Europe occidentale», Droit et société, 1993, n. ${ }^{\circ} 23 / 24$, p. 170.

4. A. Bersolle, op. cit., p. 451. 
ralismo conyugal" 5 o por lo menos "el enterramiento de la necesidad reproductiva" derivada del matrimonio heterosexual ${ }^{6}$ terminó por triunfar.

La evolución de una era familiar centrada en la autoridad patriarcal, la familia legítima y el matrimonio burgués, a una era orientada en la evanescencia jerárquica y estructuras familiares y conyugales múltiples, se ha desarrollado con el aval de las Cortes constitucionales y Cortes supremas con competencias en materia constitucional. Atrapados entre la voluntad del legislador y la fuerza persuasiva de los derechos humanos, los jueces constitucionales en su mayoría han acompañado favorablemente esta metamorfosis de civilizaciones. Sin embargo, un panorama general permite destacar un enfoque asimétrico

14 respecto al papel del juez frente a las elecciones sociales.

Respecto a los asuntos relacionados con el pluralismo conyugal, las Cortes constitucionales no se han mostrado muy emprendedoras pues ,en general, han considerado que las cuestiones relacionadas con la reconfiguración de las estructuras conyugales tenían que ser discutidas en los debates democráticos del Congreso. Los jueces constitucionales han mostrado el mayor respeto por las decisiones de los legisladores, que son los únicos que pueden y deben decidir cuándo y cómo apreciar las evoluciones de los valores
(I). Esta reserva estratégica no es una marca de la jurisprudencia de las Cortes constitucionales en materia de derechos individuales. En este caso es la imposición del derecho internacional y europeo de los derechos humanos, así como la necesidad de transposición del derecho derivado de la unión, las que dieron origen a verdaderas políticas jurisprudenciales en rechazo de comportamientos discriminatorios en contra de la mujer (pero también de los hombres), de los niños, extranjeros, homosexuales o transexuales, ancianos, etc., pues en muchas ocasiones las decisiones del legislador como las interpretaciones de los jueces ordinarios han sido desaprobadas sobre la base de la igualdad o dignidad.

\section{La reserva constitucional}

Aunque la jurisprudencia de las Cortes constitucionales sobre las evoluciones de las formas conyugales se caracterizó por la creciente consideración de los derechos fundamentales, principio de igualdad y su corolario la no discriminación, este proceso no se realizó sin tomar en cuenta la voluntad de los representantes del pueblo, pues siempre se respeta al legislador. Para poder medirlo, desarrollaremos rápidamente su acción legislativa en materia “conyugal”, lo que nos permitirá determinar el alcance de las intervenciones de las Cortes constitucionales.

5. D. Borillo, «Pluralisme conjugal ou hiérarchie des sexualités: la reconnaissance juridique des couples homosexuels dans l’Union européenne», Revue de droit de McGill, 2001, pp. 875-922.

6. M. O. Sánchez Martínez, «Constitución y parejas de hecho. El matrimonio y la pluralidad de estructuras familiares», Revista española de Derecho constitucional, enero-abril de 2000, p. 45. 


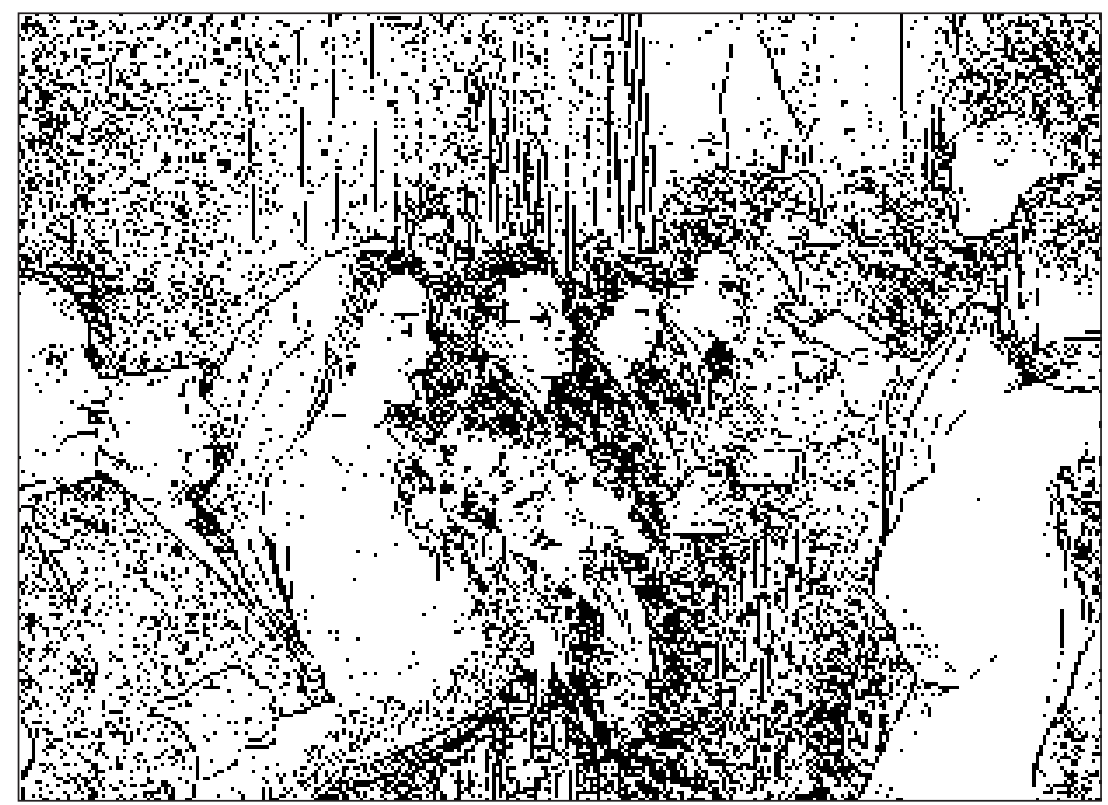

Pasamos de la sacralización de un modelo familiar único, fundamentado en la familia legítima, cuyo objetivo era asegurar la estabilidad del cuerpo social por la transmisión del patrimonio, a la valorización de otras estructuras familiares, en particular la familia natural. gia comparativa ha conducido a quince Estados miembros de la UE a reconocer un estatuto específico para las parejas homosexuales con la implementación de la "unión civil", 7 sin reconocerles todos los derechos derivados del matrimonio. Esta denominación genérica, que se declina bajo diferentes apelaciones según los Estados, ${ }^{8}$ constituye el emblema de las nuevas formas conyugales. ${ }^{9}$ Pese a la estrecha relación entre estas modalidades no se puede hablar de armonización, pues se diferencia la unión civil “institucional” de la unión civil "contractual". La primera es estrictamente reservada a las parejas homosexuales y permite un reconocimiento oficial, con condiciones y modalidades pa-
La construcción de la Unión Europea (UE) propició la circulación de los modelos legislativos y las soluciones jurisprudenciales. De hecho, la siner- recidas al matrimonio, ${ }^{10}$ mientras que la segunda está abierta a los homosexuales y heterosexuales, lo que implica la generación de formalidades y

7. Dinamarca (1999), Suecia (1994), los Países Bajos (1998), Francia (1999), Bélgica (2001), Alemania (2001), Portugal (2001), Finlandia (2001), Luxemburgo (2004), Reino-Unido (2006), Eslovenia (2006), República Checa (2006), Hungría (2007), Austria (2010) e Irlanda (2011) se inscriben en la vía de la unión marital de hecho entre personas del mismo sexo.

8. En Alemania es conocido como la asociación de vida, en Bélgica como la cohabitación legal, en Francia como el Pacto civil de solidaridad (PACS) y en el Reino Unido como la asociación civil.

9. H. Fulchiron, «Mariages et partenariats homosexuels en droit international privé français», RIDC, 2006, pp. 409-436.

10. Alemania, Dinamarca, Finlandia, Islandia, Noruega, Reino Unido, Suecia, Suiza, v. F. Granet-Lambrechts, «La diversité des modes de conjugalité: panorama de droit comparé», in H. Fulchiron (dir), Mariage-conjugalité, parenté-parentalité, Paris, Dalloz, 2009, p. 6. 
efectos distintos del matrimonio. ${ }^{11}$ Debido a la evolución de la moral, seis países miembros de la UE-dentro de los cuales cinco ya habían adoptado una legislación sobre la unión civil entre personas del mismo sexo- iniciaron una revolución legislativa cuando impulsaron la lógica igualitaria a su máximo y concedieron a las personas homosexuales los mismos derechos derivados del matrimonio. ${ }^{12}$ Los Países Bajos (2001), Bélgica (2003), España (2005), Suecia (2009), Portugal (2010) y Dinamarca (2012) están encabezando en Europa un movimiento de naturaleza global. Además de Noruega (2009) e Islandia (2010) -países europeos pero no miembros de la Uniónel proceso igualitario se manifestó también en tierras lejanas, donde la relevancia de la religión católica no dejaba predecir esta evolución. Así, 16 países como Argentina (2010), algunos Estados Federados de México y de Estados Unidos, África del Sur (2006) y Canadá (2005) siguieron el movimiento. Este proceso está en marcha hasta el punto que otros países democráticos indujeron el debate en su agenda política. ${ }^{13}$
Este rápido panorama legislativo era necesario para medir las intervenciones de las Cortes constitucionales. Los litigios constitucionales en relación con las diversas formas conyugales demuestran un gran respeto (por no decir prudencia) hacia los representantes del pueblo. Cuando estos últimos decidieron no "cruzar el Rubicón” y atenerse a la creación de "la unión civil”, las Cortes constitucionales validaron esta decisión (A). Cuando optaron por la ex tensión de los beneficios del matrimonio a las parejas homosexuales, decidiendo dar un paso importante en términos cultural, social y psicológico, es decir en términos de civilización -para retomar la fórmula preliminar de nuestro estudio- esta decisión fue respetada (B). Este respeto por las decisiones de los legisladores también se ha visto reflejado en la política jurisprudencial de la Corte Europea de Derechos Humanos. ${ }^{14}$ Los jueces están en la misma sintonía cuando se trata de "ceñirse a la norma” y no olvidarse del propietario de las opiniones sociales en las democracias.

11. Francia, Bélgica, Luxemburgo.

12. Para un análisis sociológico y jurídico, ver. J. Bustillos, «Derechos humanos y protección constitucional. Breve estudio sobre el matrimonio entre personas de mismo sexo en México y en perspectiva comparada», Boletín mexicano de derecho comparado, 2011 , n. ${ }^{\circ}$ 132, pp. 1017-1045. Para un estudio de fondo sobre el estado del derecho en varios países, ver. Homoparentalité? Approche comparative, Paris, SLC, 2012. Asimismo se puede consultar el estudio de derecho comparativo dirigido por el Senado en el marco de la preparación del proyecto sobre el matrimonio de las parejas del mismo sexo en Francia: Étude de législation comparée. Mariage des personnes de même sexe et homoparentalité, n. ${ }^{\circ}$ 229, novembre 2012.

13. A esta fecha (inicio de enero de 2013), Andorra, Francia, el Reino Unido y Uruguay están discutiendo la posibilidad de extender la institución del matrimonio a las parejas del mismo sexo.

14. CEDH, GC, 24 juin 2010, Shalk et Kopf c/ Autriche: «en l'absence de dénominateur commun amplement partagé (.../...) on ne saurait tirer de l'article 12 une obligation faite à l'État de reconnaître aux homosexuels le droit de se marier», \$62 [l'institution du mariage homosexuel est un choix qui relève du seul législateur national, qui peut ou non, décider de le créer].

Criterio Jurídico Garantista. Año 5, No. 8. Ene.-Jun. de 2013. ISSN: 2145-3381. Fundación Universidad Autónoma de Colombia, Bogotá. 


\section{El respeto por las diferencias instituidas}

Respecto a la "unión civil entre personas del mismo sexo", las Cortes constitucionales han preferido respetar las diferencias erigidas por los legisladores. Ratificaron las diferencias de trato con el matrimonio o el concubinato, considerándolos legítimos. Por ello, en Francia -país que, en conjunto con Bélgica y Luxemburgo optó por una fórmula particularmente diferenciada del matrimonio- el Tribunal Constitucional validó la ley que estableció el PACS en 1999. ${ }^{15}$ Pese a que la legislación fue reescrita varias veces debido a numerosas reservas interpretativas, las diferencias de situaciones y de régimen terminaron por ser adoptadas. Es sobre esta base que el juez constitucional validará en muchas ocasiones las diferencias derivadas del estatuto de parejas "pacsadas ${ }^{16 "}$ y "casadas". La decisión del 6 de octubre de 2006 es, sin lugar a dudas, la más reveladora al respecto. ${ }^{17}$ En esta decisión el Tribunal recordará su jurisprudencia clásica en materia de igualdad, que

no se opone a que el legislador arregle de manera diferente tinta, situaciones disímiles, ni tampoco a que transgreda el principio de igualdad, siempre y cuando la diferencia de trato sea en relación directa con el objeto que la ley establece. Por lo tanto, el Tribunal validará las diferencias instituidas por el artículo 365 del Código Civil en materia de adopción. El considerando n. ${ }^{\circ} 9$ de la sentencia anteriormente mencionada y su respectivo comentario establecen claramente las principales razones que llevaron al Tribunal a ser prudente. ${ }^{18} \mathrm{El}$ Tribunal no puede y no quiere substituir al legislador en temas como la paternidad para los homosexuales, "modelo de la problemática de la sociedad. ${ }^{19}$

El Tribunal constitucional alemán, en su decisión del 17 de julio de 2002, aprobó también algunas diferencias creadas por el legislador en la Ley

15. Cons. const., déc. n. ${ }^{\circ}$ 99-419 DC del 9 de noviembre de 1999, Ley sobre el pacto civil de solidaridad.

16. Parejas que se unieron bajo la formalidad del pacto civil de solidaridad (contrato francés de unión civil).

17. Cons. const. déc. n. ${ }^{\circ}$ 2010-39 QPC del 6 de octubre de 2010, Isabelle D. et Isabelle B. [Adopción para parejas afuera del matrimonio].

18. Considerando n. ${ }^{\circ} 9$ : «Considérant, en second lieu, qu’en maintenant le principe selon lequel la faculté d'une adoption au sein du couple est réservée aux conjoints, le législateur a, dans l'exercice de la compétence que lui attribue l'article 34 de la Constitution, estimé que la différence de situation entre les couples mariés et ceux qui ne le sont pas pouvait justifier, dans l'intérêt de l'enfant, une différence de traitement quant à l'établissement de la filiation adoptive à l'égard des enfants mineurs ; qu'il n'appartient pas au Conseil constitutionnel de substituer son appréciation à celle du législateur sur les conséquences qu'il convient de tirer, en l'espèce, de la situation particulière des enfants élevés par deux personnes de même sexe ; que, par suite, le grief tiré de la violation de l'article 6 de la Déclaration de 1789 doit être écarté».

19. El comentario: «Le Conseil a donc jugé, en octobre 2010, qu’il en va de l'«homoparentalité » comme il en allait, en janvier 1975, de l'interruption volontaire de grossesse ou, en juillet 1994, de la sélection des embryons: cette question constitue l'archétype de la question de société dont la réponse, en France, appartient au législateur», v. Commentaire de la déc. n. ${ }^{\circ}$ 2010-39 QPC du 6 octobre 2010, site Internet du Cons. Const. p. 10. Cabe recordar que el Tribunal Europeo confirmo esta posición en el Caso Gas y Dubois v/France del 15 de marzo de 2012. También es preciso señalar que Jean Paul Costa, en su opinión concordante, dejó claro del Código Civil. Sin embargo se unió a la decisión de la Corte.

Criterio Jurídico Garantista. Año 5, No. 8. Ene.-Jun. de 2013. ISSN: 2145-3381. Fundación Universidad Autónoma de Colombia, Bogotá. 


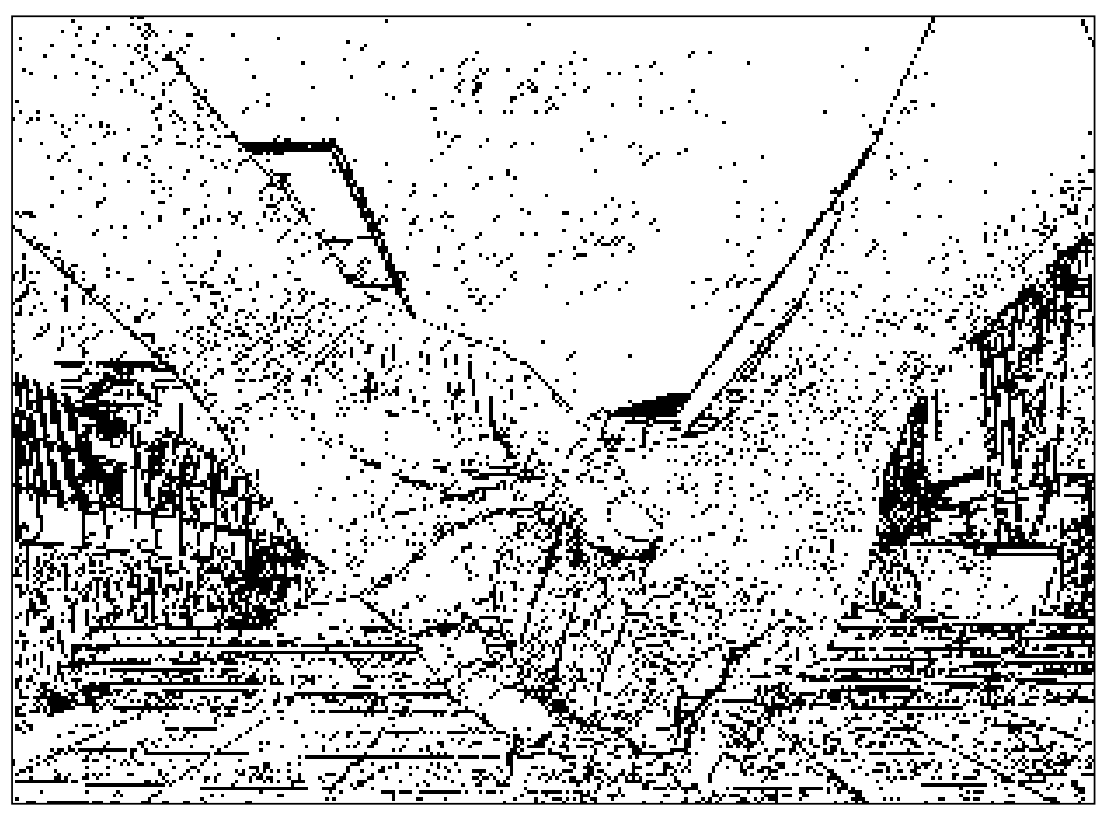

Cuando los representantes del pueblo optaron por la extensión de los beneficios del matrimonio a las parejas homosexuales, decidiendo dar un paso importante en términos cultural, social y psicológico, es decir en términos de civilización - para retomar la fórmula preliminar de nuestro estudio- esta decisión fue respetada.

del 16 de febrero de 2001 sobre el contrato para la vida en común. ${ }^{20}$ Respecto al argumento de la violación del artículo 6.1 de la Ley fundamental, que prohíbe al legislador atentar contra la libertad del matrimonio -el Tribunal de Karlsruhe consideró que la concepción del matrimonio no se encontraba desvalorizada, ya que no quitaba al matrimonio sus ventajas- la nueva institución no redujo los derechos de las personas casadas porque eran situaciones diferentes, por lo que se trataba de parejas homosexuales. El argumento de la violación del principio de igualdad también se rechazó. Este argumento había sido alegado por lo que la ley alemana ya excluía de la institución de la unión civil los parientes cercanos casados (ascendientes, descendientes, hermanos). ${ }^{21} \mathrm{De}$ manera general, podemos decir que la jurisprudencia alemana siempre ha intentado encontrar el punto de equilibrio entre el principio general de igualdad y la protección del matrimonio consagrada en el artículo 6 de la ley fundamental que estipula lo siguiente: "el matrimonio y la familia están bajo la protección especial del Estado”. En esas condiciones, el juez de Karlsruhe no duda en expedir, siempre y cuando no afecte la igualdad entre los niños, garantías de constitucionalidad a las diferencias de trato entre personas casadas y las demás. ${ }^{22}$

20. Tribunal Constitucional alemán, 17 de julio de 2002, Bverf GE, tome 105, p. 313, v. M. Fromont, «République Fédérale d’Allemagne: la jurisprudence constitutionnelle en 2002», RDP, 2004, spec. pp. 1136-1138.

21. En Francia, la exclusión atenía a las personas que tenían una relación parental (artículo 515-2 del Código Civil).

22. Tribunal Constitucional alemán 28 de febrero de 2008, BVerf GE, tome 117, p. 316, v. M. Fromont, «Jurisprudence constitutionnelle de la République fédérale d'Allemagne (2007)», RDP, 2008, p. 1701. En este caso el tribunal valida una disposición del 
En este concierto de decisiones constitucionales hubo una disonancia, por no decir disidencia, ya que la palabra sería exagerada. En el marco de una reforma importante del Código Civil y del Código de la Familia, se puso una demanda ante el Tribunal Constitucional húngaro ${ }^{23}$ contra la Ley n. ${ }^{\circ}$ 148/2007 que regía la unión civil. El legislador había optado por abrir la unión civil a parejas heterosexuales y homosexuales con efectos jurídicos similares a aquellos del matrimonio (excepto los relacionados con la adopción y el apellido $\left.^{24}\right)$. La decisión del juez constitucional ${ }^{25}$ tuvo dos tiempos: primero, el juez admite la constitucionalidad de la creación de la institución de la “unión civil”, y dos, la Ley de 2007 está in casu declarada inconstitucional y anulada. ${ }^{26}$ Jugando la carta del derecho comparativo, y valorando las decisiones constitucionales alemanas y francesas, el juez constitucional húngaro destacó las diferencias que existen entre una labor legislativa que detalle los diferentes derechos y obligaciones derivados de la institución de la unión civil y aquella que queda imprecisa. Cabe destacar que la ley húngara estipula lo siguiente: "Salvo que la ley disponga lo contrario, las normas relativas al matrimonio se aplicarán mutatis mutandis a la unión civil”. Por lo tanto el Tribunal sostuvo que en virtud de la protección de la institución matrimonial consagrada en el artículo $15^{27}$ de la antigua Constitución húngara, "el legislador no tenía competencia para extender vía remisión general la casi totalidad de las obligaciones e institucionales relacionadas con el matrimonio ${ }^{28}$." La censura fue el resultado de una técnica legislativa cómoda y rápida (la técnica de la remisión), en la que su intención era claramente desaprobar la asimilación de la unión civil a la institución matrimonial. ${ }^{29} \mathrm{El} 25$ de abril de 2011 , la adopción de una nueva Constitución bajo el mandato del ultraconservador Viktor Orban ${ }^{30}$-cuyo conte-

código social, que estipula que «los gastos relacionados a intervenciones medicales orientadas a provocar el embarazo, solo se desembolsarán a las personas casadas".

23. Se trataba de una demanda colectiva entre particulares, diputados del partido cristiano-demócrata y asociaciones de defensa de los intereses de la familia.

24. Hay que sumarles las condiciones de disolución del matrimonio (ante notario y no ante el juez), la diferencia sobre la edad (18 años para la unión civil, mientras que para el matrimonio se puede bajar a 14 años para las mujeres y 16 para los niños bajo condiciones estrictas.

25. Tribunal Constitucional húngaro, resolución 154/2008 (XII.17) AB, v. P. Kovács, «Hongrie», Table Ronde Constitution et Famille(s), AIJC, 2008, pp. 244 et s.

26. No pudo entrar en vigor el primero de enero de 2009.

27. El artículo estipula: «La República de Hungría protege la institución matrimonial y familiar».

28. P. Kovács, «Hongrie», Table Ronde Constitution et Famille(s), AIJC, 2008, p. 245.

29. Cabe destacar que la técnica de «remisión» fue una regla en las legislaciones de los países escandinavos, ver. T. Groppi, «La nouvelle famille», AIJC 2007, Famille et droits fondamentaux, 2008, p. 538.

30. La nueva Constitución húngara, adoptada por la Asamblea Nacional el 18 de abril de 2011 y firmada el 25 de abril de 2011 por el Presidente de la República, el señor Viktor Orban, entró en vigor el 1 de enero de 2012. 
nido provocó un sentimiento de vergüenza ${ }^{31}$ no permitió una reintroducción del tema. ${ }^{32}$ De todos modos, la excepción húngara confirma la regla según la cual se respeta la voluntad de los legisladores, independientemente de la forma de unión civil que decidieron establecer.

\section{El respeto de las similitudes reivindicadas y aprobadas}

Respecto al matrimonio entre personas del mismo sexo, las Cortes constitucionales europeas respetaron las similitudes reivindicadas por los homosexuales y aprobadas por los legisladores. Sin embargo, no quisieron eludir y sobrepasar las disposiciones de los códigos civiles, sin que 20 los legisladores hubieran decidido modificar radicalmente el estado clásico de las relaciones conyugales, fundamentadas en el matrimonio entre un hombre y una mujer.

Las demandas por inconstitucionalidad de las disposiciones "clásicas" de los códigos civiles no han prosperado (Francia, Portugal), mientras que las leyes que reconocieron el matrimonio entre las personas del mismo sexo siempre han sido declaradas constitucionales. En otras palabras, antes de la intervención de los legisladores no hubo una interpretación evolutiva de las disposiciones de los códigos civiles, mientras que las transformaciones de valores fueron aprobadas una vez decididas por los representantes del pueblo. Antes: prudencia y espera; después: respeto y validación. Ahora, miremos algunos ejemplos emblemáticos, como el caso de Portugal, que optó por las dos actitudes (prudencia y respeto), mientras otros países, en conformidad con la configuración política y constitucional del país, optaron por esperar (Italia y Francia) o por el respeto, en el caso de España.

Portugal logró demostrar -en un tiempo particularmente corto- su capacidad de espera/ prudencia para después respetar las decisiones de los legisladores. El 9 de julio de 2009, el Tribunal constitucional desaprobó un recurso presentado contra una decisión de justicia, la cual había rechazado a las dos demandantes la posibilidad de contraer el matrimonio civil. ${ }^{33}$ En este caso, se trataba de saber si el artículo 1577 del Código Civil (que limita el matrimonio a la unión entre un

31. La nueva Constitución fue al origen de debates tumultuosos a nivel nacional e internacional. Ver. V. les avis CDL (2011) o16 et CDL (2011) 001 de la Commission Européenne pour la Démocratie par le Droit (la Commission de Venise), la résolution n. ${ }^{\circ}$ 12490 déposée le 25 janvier à l'Assemblée parlementaire du Conseil de l'Europe, les déclarations du Conseil et de la Commission ainsi que la résolution du Parlement Européen du 5 juillet 2011.

32. La posibilidad de la unión civil como institución alternativa es muy escasa debido a la configuración política actual. El contenido del artículo L de la nueva Constitución lo demuestra: “1. Hungría defiende la institución del matrimonio como unión voluntaria entre un hombre y una mujer así como la familia como base fundamental para la supervivencia de la nación. 2. Hungría promueve la natalidad. 3. La defensa de la familia estará reformada por ley orgánica”.

33. Tribunal constitucional portugués, 9 de julio de 2009, n. ${ }^{\circ}$ 359-2009, v. J. Miranda, «Portugal», AIJC 2009, 2010 , seco. pp. $810-817$. 
hombre y una mujer) estaba de conformidad con el artículo 36 de la Constitución portuguesa. ${ }^{34}$ La repuesta fue positiva y los argumentos fueron los siguientes: primero, si el legislador hubiera querido modificar el Código Civil introduciendo una modificación en la definición del matrimonio para incluir a las personas del mismo sexo, hubiera tenido muchas oportunidades para hacerlo, en particular con la reforma del año $2004 ;{ }^{35}$ segundo, si bien es cierto el matrimonio no presupone la posibilidad o la voluntad de procrear, la relación entre matrimonio y procreación existe. ${ }^{36}$ Finalmente, una eventual decisión de inconformidad sería una manera de crear una "decisión aditiva”, es decir, que modifique por vía jurisprudencial la institución matrimonial, lo que afectaría su legitimidad. Estos argumentos pusieron un fin momentáneo al debate, dejando sin embargo una puerta entreabierta para una posible evolución, ya que el tribunal rechazó la interpretación según la cual la Constitución se limitaría a reconocer una definición única del matrimonio (párrafo 10).

Esta apertura fue adelantadora, puesto que un año después el legislador decidió abrir el matrimonio a los homosexuales, ${ }^{37}$ elección social que fue aprobada por el Tribunal constitucional el 9 de abril de 2010. ${ }^{38}$ Los jueces estimaron en once votos contra dos, que el matrimonio era "un concepto abierto”, susceptible de diversas opciones políticas, sociales o éticas y que su papel se limitaba a hacer respetar "las concepciones dominantes" del momento.

La Corte constitucional italiana mantiene hasta ahora un enfoque prudente. Cabe destacar que Italia no se unió a los Estados europeos, que legalizaron el matrimonio homosexual, ni tampoco dispone de una legislación sobre formas conyugales alternativas como el PACS (Francia). Cuando el Tribunal de Venecia interpuso ante la Corte constitucional una demanda para cuestionar la constitucionalidad de la disposición del Código Civil que limita el matrimonio a las parejas heterosexuales y su conformidad con el artículo 3 de la Constitución, que prohíbe cualquier forma de discriminación, la Corte afirmó que la exclusión del matrimonio para las personas del mismo sexo no podía ser considerada inconstitucional, ${ }^{39}$ decisión que será confirmada por la Corte de

34. Todos tendrán derecho a constituir una familia y a contraer matrimonio en condiciones de igualdad plena. 2. La Ley regulará los requisitos y los efectos del matrimonio y de su disolución, por muerte o divorcio, independientemente de la forma de celebración.

35. Bajo la influencia de la Carta de los derechos fundamentales de la Unión, en particular con su artículo 2 1, el párrafo 2 del artículo 13 de la Constitución fue modificado para incluir la orientación sexual como nuevo motivo prohibido de no-discriminación.

36. J. Miranda, op. cit., p. 812.

37. Loi nº 9 du 31 mai 2010. L’article 1577 est libellé désormais comme suit: «Le mariage est le contrat conclu entre deux personnes qui aspirent à constituer une famille au moyen d'une vie commune».

38. Tribunal constitucional portugués, 9 de abril de 2010. La ley había sido sometida al juez constitucional por el Presidente de la República, el conservador Anibal Cavacco Silva.

39. Corte constitucional italiana, abril de 2010, n. $^{\circ} 138 / 210$. 
Casación. ${ }^{40}$ Para motivar su decisión la Corte se fundamentó en el artículo 29 de la Constitución, que define la familia como "la sociedad natural derivada del matrimonio". Además de este argumento, la Corte se refirió también a la voluntad de los fundadores del texto constitucional de 1947, que seguramente no habían contemplado la figura de parejas homosexuales en el momento de su redacción. El Consejo Constitucional francés llegó a la misma conclusión, utilizando sin embargo argumentos distintos. El 28 de enero de 2001, en el marco de una cuestión prioritaria de constitucionalidad, ${ }^{41}$ el Consejo, en su considerando n. ${ }^{\circ} 5$ junto con el considerando n.o 9, evidenció claramente la prevalencia que tiene el legislador sobre el Consejo Constitucional ${ }^{42} \mathrm{y}$ consideró, articulándose estratégicamente con la 22 jurisprudencia judicial, ${ }^{43}$ que los artículos $75 \mathrm{y}$
144 del Código Civil estaban en conformidad con la Constitución. Al valorizar, incluso sacralizar el papel del legislador sobre este tipo de problemáticas de la sociedad, el Consejo deja una puerta abierta a las consecuencias de un posible cambio de perspectiva legislativa sobre el matrimonio entre personas del mismo sexo, en el sentido que reconoce la soberanía del legislador para rechazar el matrimonio homosexual; es también una manera de reconocer su soberanía para consagrarlo.

En España se presentó un caso inédito que demuestra cómo el tiempo y la evolución del derecho en otros países del mundo influyó en la transformación de la legislación. De hecho, aunque la mayoría socialista liderada por el gobierno de José Luis Rodríguez Zapatero legalizó el matrimonio homosexual en el año $2005,{ }^{44}$ el

40. Sin embargo la confirmación ha sido objeto de un matiz respecto al carácter natural del matrimonio: Corte de Casación italiana, 15 de marzo de 2012, n. ${ }^{\circ}$ 4184, ver note de F. Laffaille, Constitutions, 2013.

41. Cons. const. déc. n. ${ }^{2010-92}$ QPC du 28 janvier 2011, Mme Corinne C. et autre [Interdiction du mariage entre personnes de même sexe].

42. El considerando . $^{\circ} 5$ dice los siguiente: “Considerando que en virtud del artículo 34 de la Constitución, La ley fijará las normas sobre la capacidad de las personas, regímenes matrimoniales, sucesiones y donaciones”, el legislador podrá, en el ejercicio de su competencia, adoptar nuevas disposiciones, por lo que le corresponde apreciar la oportunidad de modificar o anular textos anteriores y substituirlos con otras disposiciones siempre y cuando respete las garantías legales de las exigencias constitucionales. Que el artículo 61 y 61-1 de la Constitución en ningún momento le otorga al Consejo Constitucional un poder general de apreciación y decisión de la misma naturaleza que aquello del parlamento; que este artículo, solo le da competencia para pronunciarse sobre la conformidad de una disposición legislativa con los derechos y libertades garantizados por la Constitución”, y considerando 9 in fine "que no le corresponde al Consejo Constitucional sustituir al legislador en la apreciación de esta diferencia de situación, que por lo tanto, la demanda basada en la violación del artículo 6 de la Declaración de 1789 debe ser desestimada.

43. En el considerando n. ${ }^{\circ} 3$ se refirió a la jurisprudencia de la Corte de casación del 13 de marzo de 2007, la cual había claramente planteado, en virtud del derecho positivo, la alteridad sexual como condición al matrimonio. Por lo tanto, la Corte de Casación rechazó la demanda contra la sentencia de la Corte de apelación de Bordeaux, confirmando la decisión de los jueces de la primera instancia, que había cancelado el matrimonio celebrado a Bèlges (TGI Bordeaux, 27 juillet 2004; CA Bordeaux, 19 avril 2005 ).

44. Ley n. ${ }^{\circ} 13 / 2005,1^{\circ}$ de julio de 2005, por la que se modifica el Código Civil en materia de derecho a contraer matrimonio (BOE n. ${ }^{\circ}$ 157, 2 de julio de 2005). Cabe destacar que una segunda ley (n. ${ }^{\circ}$ 15/2005) introdujo modificaciones importantes al Código Civil y a la ley de procedimiento civil en materia de separación y divorcio. Ley de Enjuiciamiento Civil en materia de separación y divorcio (BOE n. ${ }^{\circ}$ 163, 9 de julio de 2005). 


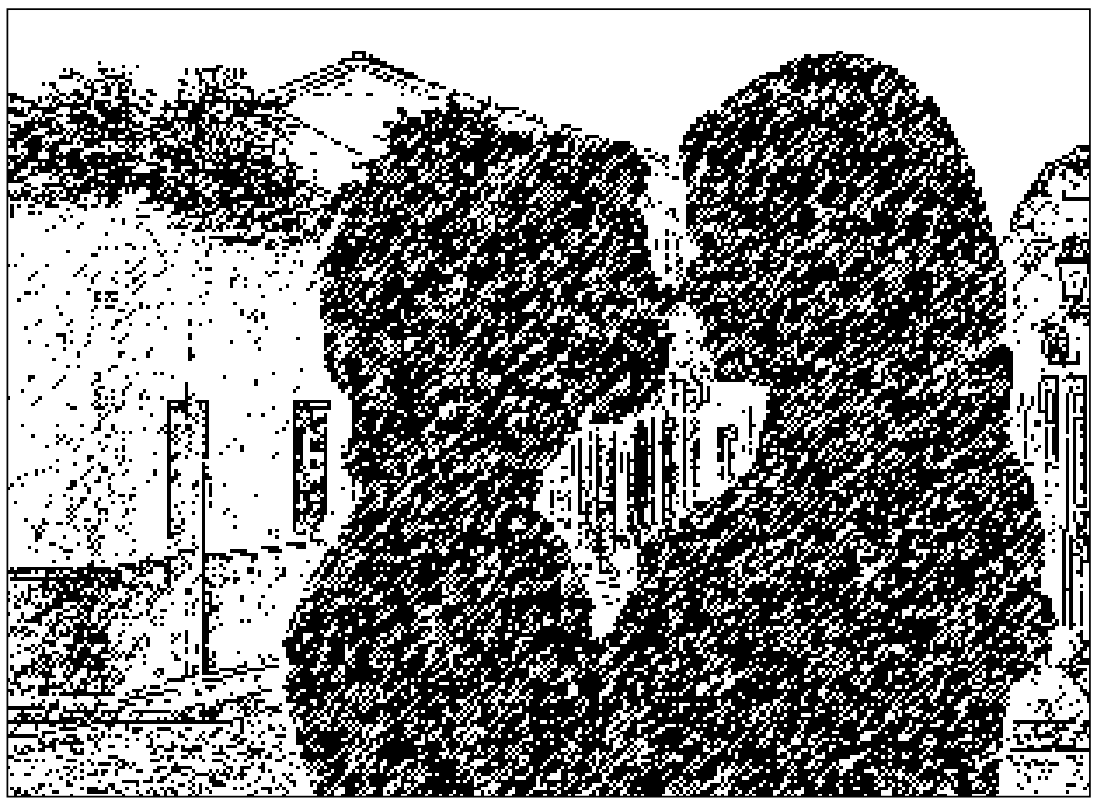

\section{En Canadá y México las leyes a favor del matrimonio entre homosexuales han sido adoptadas y declaradas constitucionales sin mayor inconveniente. Pero en otros países se reportaron soluciones divergentes, dependiendo de las reformas que realizaron los legisladores al Código Civil.}

Tribunal constitucional aprobaría la opción igualitaria del legislador hasta siete años después en una importante decisión del 6 de noviembre de 2012. ${ }^{45}$ Aunque el artículo 32 de la Constitución dispone en su primer párrafo que "el hombre y la mujer tienen derecho a contraer matrimonio con plena igualdad jurídica”, el legislador utilizó las potencialidades del segundo párrafo "La ley regu- lará las formas de matrimonio, la edad y capacidad para contraerlo, los derechos y deberes de los cónyuges, las causas de separación y disolución y sus efectos ", para eludir la referencia a la alteridad sexual. ${ }^{46}$ En la época en la que se promulgó la ley -la cual causó grandes discusiones dentro de la comunidad de juristas ${ }^{47}$ - se había presumido el futuro enfoque del juez constitucional al res-

45. Tribunal constitucional español, 6 noviembre de 2012, $\mathrm{n}^{\circ}$ 198/2012 (BOE, $\mathrm{n}^{\circ} 286$ del 28 noviembre 2012). La ley española n. ${ }^{\circ}$ 13/2005 del 1 julio de 2005 - preparada por el ministro de Justicia, el señor Fernando López Aguilar del gobierno de J.-L. Rodríguez Zapatero- ha sido presentada ante el Tribunal constitucional por 71 diputados del partido conservador, dirigido en este entonces por el conservador José María Aznar, mediante un recurso por inconstitucionalidad.

46. Los efectos del matrimonio son idénticos en todos los ámbitos, independientemente del sexo del cónyugue. Por lo tanto, las parejas homosexuales gozan de los mismos derechos y obligaciones que las parejas heterosexuales y podrán ser parte de los procesos de adopción. De esta manera, el matrimonio entre personas del mismo sexo se considerará en todos sus aspectos similar al matrimonio heterosexual. En este sentido, la ley cambió la terminología contenida en las disposiciones del Código Civil, que hacía referencia de manera explícita al sexo de los contratantes. Las indicaciones relativas al marido y a la mujer han sido remplazadas por "a los conyugues" o “a los esposos".

47. A. Barrero Ortega, «Le débat sur la légalisation du mariage homosexuel», RFDC, n. ${ }^{\circ}$ 70, 2007, pp. $249-267$. 
pecto. ${ }^{48}$ La posición que terminó por ser adoptada fue aquella de la optimización de las potencialidades del párrafo n. $^{\circ}$ del artículo 10 , relativo a la obligación de interpretar los derechos fundamentales a la luz del derecho internacional de los derechos humanos, ${ }^{49}$ lo que se verá confirmado en la práctica. De hecho, siguiendo las líneas de un enfoque dinámico denominado "el derecho vivo", interpretando el derecho constitucional español a la luz del derecho internacional de los derechos humanos, realizando un estudio comparativo con las demás situaciones en el mundo en materia de unión civil y teniendo en cuenta los miles de matrimonios entre personas del mismo sexo que se celebraron desde la adopción de la ley, el juez constitucional confirmó la constitucionalidad de la Ley de 2005.

Esos esquemas constitucionales (prudentes y respetuosos) se ven reflejados en algunas ocasiones en otras partes del mundo. En Canadá ${ }^{50}$ y México $^{51}$ las leyes a favor del matrimonio entre homosexuales han sido adoptadas y declaradas constitucionales sin mayor inconveniente. Pero en otros países se reportaron soluciones divergentes, dependiendo de las reformas que realizaron los legisladores al Código Civil. Mientras que el 3 de noviembre de 2011 el Tribunal constitucional

48. En un documento se podía leer lo siguiente: el Tribunal constitucional «optará por una interpretación exegética del artículo 32, valorizando la ortodoxia matrimonial o decidirá aprovechar las potencialidades del artículo 10.2, que estimula una interpretación de los derechos fundamentales a la luz del derecho internacional». En el caso que opte por la segunda opción, la Carta de los derechos fundamentales de la Unión Europea podría ocupar un lugar especial en su argumento. Sabemos que el Tribunal constitucional fue la primera jurisdicción constitucional que la aprovechó. Cabe recordar que el artículo 9 de la Carta, que ya había sido utilizado con audacia por la Corte de Estrasburgo, en el caso Goodwin, reconoce el derecho al matrimonio a todas las personas. v. L. Burgorgue-Larsen, «Chronique de jurisprudence européenne comparée», RDP, 2006, p. 1132.

49. E. García de Enterría, «Valeur de la jurisprudence de la Cour européenne des droits de l'homme en droit espagnol», in Protection des droits de l'homme: la dimension européenne. Mélanges en l'honneur de Gérard Wiarda, Carl Heyman Verlag KG, 1990, pp. 22 1-230, Ver también: A. Saiz Arnaiz, La apertura constitucional al derecho internacional y europeo de los derechos humanos: el artículo 10.2 de la Constitución española, Consejo General del Poder Judicial, Madrid, 1999, 302 p.; del mismo autor «La interpretación de los derechos fundamentales y los tratados internacionales sobre derechos humanos», in Casas Baamonde María Elena y RodríguezPiñero y Bravo-Ferrer, Miguel (dir.), Comentarios a la Constitución española de 1978. XXX Aniversario, Madrid, Fundación Wolters Kluwer, 2008, pp. 193-209. Asimismo en francés ver el artículo de Gómez Fernández, «Droit de l’Union Européenne et droit international depuis la perspective du droit constitutionnel espagnol», in L. Burgorgue-Larsen, E. Dubout, A. Maitrot de la Motte, S. Touzé (dir.), Les interactions normatives. Droit de l’Union Européenne et droit international, Paris, Pedone, 2012 , pp. 107-132.

50. Corte suprema de Canadá, al 9 de diciembre de 2004. Sin embargo, cabe destacar que se trataba del anteproyecto de la Ley federal sobre el matrimonio, presentado ante la Corte Suprema por el gobierno federal, para que los jueces dierán su opinión al respecto (en virtud del artículo 53 de la Ley sobre la Corte Suprema). Ver artículo de Vallières, «La prohibición del matrimonio entre cónyuges del mismo sexo como discriminación por razón de orientación sexual (un comentario a la sentencia sobre el matrimonio entre personas del mismo sexo del Tribunal Supremo de Canadá)», Revista de Derecho Político, Madrid, n. ${ }^{\circ}$ 68, 2007 , pp. $297-312$.

51. Corte Suprema de Justicia de la Nación (México), al 16 de agosto de 2010, Acción por inconstitucionalidad n. ${ }^{\circ} 2 / 10$ interpuesta por el Procurador General de la República. EL objeto de la demanda era declarar la inconstitucionalidad de los artículos 146 y 391 del Código Civil del Distrito Federal del México, que reconocían a las parejas homosexuales el derecho al matrimonio pero 
chileno eludía $^{52}$ la aplicabilidad del artículo 102 del Código Civil (que define el matrimonio como una unión entre un hombre y una mujer) a las parejas del mismo sexo, la Corte constitucional de África del Sur ${ }^{53}$ interpretaba de manera evolutiva los artículos pertinentes del Código nacional, basándose en los principios de igualdad y dignidad.

\section{El activismo constitucional}

Si bien los derechos constitucionales nunca han negado los principios de igualdad y nodiscriminación, las reformas de los legisladores sobre el derecho de las personas y de la familia solo han sido posibles gracias a la influencia de los derechos europeos. De hecho, en muchas ocasiones fueron las Cortes constitucionales las que activaron el movimiento de la reforma, censurando numerosas leyes contrarias a los estándares europeos (A). En determinadas cir- cunstancias se observaron también las virtudes modificadoras (algunos dirían subversivas) del “derecho-principio", en particular a través del concepto fundamental de dignidad (B). De hecho, los principios de igualdad y no discriminación, así como el concepto de dignidad, han sido los vectores de profundos cambios en el orden jurídico constitucional, construyendo un mundo en el que las características propias de las personas no pueden ser el origen de tratos discriminatorios.

\section{El binomio igualdad/no-discriminación}

La importancia creciente del individuo y de sus derechos se dio bajo la presión de la jurisprudencia de Estrasburgo (CEDH), que venía persiguiendo desde hace mucho tiempo todas las diferencias discriminatorias de trato, siempre y cuando no respondieran a un objetivo legítimo (artículo 14 y 1 del protocolo n. $\left.{ }^{\circ} 12\right) .{ }^{54}$ En el derecho de

también a la adopción. V. L. Burgorgue-Larsen, «iVivan las bodas! Quand le mariage homosexuel est saisi par l’internationalisation du dialogue des juges», Constitutions, octobre-décembre 2010, n. ${ }^{\circ}$ 4, pp. 557-561. V. también E. Rodríguez Martínez, «Los matrimonios homosexuales en el Distrito Federal. Algunas consideraciones en torno a la reforma de los códigos Civil y de Procedimientos Civiles», Boletín Mexicano de Derecho Comparado, n. ${ }^{\circ}$ 128, mayo-agosto 2010.

52. Tribunal constitucional chileno, al 3 de noviembre de 2011 , rol n. ${ }^{\circ} 1881$ - 10 NA. En este caso, el Tribunal se declaró incompetente y remitió la pelota al legislador. Sin embargo, se emitieron opiniones diferentes, alegando en virtud de los principios y valores constitucionales, argumentos de fundo sobre la necesidad de reglamentación civil del matrimonio. En particular, hubo un voto disidente, que estimaba que el examen de la cuestión era necesaria para responderla positivamente. v. J. C. Singh, «Matrimonio civil y Constitución política: la sentencia del Tribunal constitucional sobre matrimonio para personas del mismo sexo», Anuario de derechos humanos, 2012, pp. 155-164.

53. Corte Constitucional de África del Sur, al primero de diciembre de 2005, casos n.o CCT 60/04 y n. ${ }^{\circ}$ CCT 10/05. Basándose en el artículo 9 (3) de la Constitución surafricana, la Corte consideró que la discriminación basada en la orientación sexual era inconstitucional y dio un plazo de un año al legislador para que reformará le ley sobre el matrimonio y sustituyera las palabras «marido»y «esposa» por «cónyuges».

54. Sudre F., Surrel H., (dir.), Le droit à la non discrimination au sens de la Convention européenne des droits de l'homme, Bruxelles, Bruylant, 2008, 474 p. 
la Unión, el auge de la corriente igualitaria se inició cuando adoptaron e implementaron el artículo 19 del TFUE (ex artículo 13 del TCE). Las transposiciones de las famosas directivas "antidiscriminación" transformaron varios sistemas jurídicos, prohibiendo tanto las discriminaciones formales y directas como las discriminaciones materiales e indirectas. Si a eso le sumamos la fuerza vinculante de la Carta de los Derechos Fundamentales de la Unión Europea (CDFUE), en la que los motivos prohibidos de discriminación son particularmente extensos, nos podríamos atrever a decir que el siglo XXI será "igualitario o no”, para parafrasear una fórmula famosa. Por ello, la fuerza del principio de no-discriminación se insertó en todas las cuestiones relacionadas con la igualdad de los sexos y de las personas, 26 independientemente de su edad (niños/ancianos), nacionalidad (extranjeros, extranjeros en situación regular o irregular/refugiados políticos), orientación sexual (homosexual/transexual), situación profesional (empleado/desempleado - civil/militar) o su situación personal (casadas, asociadas, en concubinato, solteros, etc.).

Estudiamos unos de esos temas en los cuales las Cortes constitucionales acompañaron este movimiento censurando la labor de los legisladores mediante la desaprobación de las decisiones emitidas por los jueces de primera o segunda instancia, por no haber tomado en serio estas evoluciones de la sociedad. No se tratará de presentar un cuadro completo, pues sería imposible dada la amplitud del tema, ${ }^{55}$ sino más bien, como parte del "puntillismo doctrinal”, algunas referencias "impresionistas".

Empezamos por el litigio relacionado con la igualdad de los sexos. De las relaciones hombresmujeres en el ámbito profesional a las que se forjaron en el mundo de la pareja y la familia (en particular con la cuestión del apellido, la autoridad parental, las pensiones de reversión, el estatuto de los niños, etc.), el campo de estudio es inmenso. Intentaremos solamente esbozar las grandes líneas de algunas tendencias de fondo. El derecho de la Unión ha sido precursor en la valorización de la igualdad hombre/mujer en el ámbito profesional (remuneración, trabajo de medio tiempo, licencia por enfermedad, licencia por maternidad). ${ }^{56}$ La jurisprudencia de la Corte de justicia consistió en desalojar los sistemas en los que la discriminación -bien sea inexistente prima facie - se encontraba escondida detrás de textos que establecían discriminaciones indirectas. Efectivamente, en muchas ocasiones estas son disimuladas detrás de una norma, práctica o un criterio aparentemente neutro y vienen afectando los derechos de grupos considerados como vulnerables. Algunas de las Cortes constitucionales se han apoderado del concepto de discriminación indirecta mediante un uso acertado del

55. Los temas estudiados han sido decididos tras una selección discrecional, que asumimos. En el marco de este estudio restringido, no fue posible abordar todos los temas, en todos los países de la Unión Europea y menos en aquellos del Consejo de Europa.

56. La Corte de Justicia en su sentencia Defrenne II del _ de abril de 1976, afirmó que el antiguo artículo 141 del TCE, la igualdad de trato entre hombres y mujeres no solo tenía un objetivo económico, sino que tenía también una pretensión social. 
derecho internacional y europeo de los derechos humanos. España, con su famoso artículo 10.2, constituye un arquetipo al respecto. El Tribunal no dudó en censurar al legislador (es decir a la Ley de 1995 sobre el estatuto de los trabajadores), cuando introdujo un sistema de cálculo de cotización social específico para los trabajadores de medio tiempo. Aparentemente neutro, ${ }^{57}$ este criterio escondía una discriminación indirecta, en la medida en que la mayoría de los trabajadores afectados eran en realidad mujeres. El criterio se toma también en serio en el Reino Unido, ya que en el caso R. v. Secretary of State for Employment, exparte Equal Opportunities Commission, los Lord decidieron que la disposición de la Employment Protection (Consolidation) Act 1978 -que limitaba los trabajadores de medio tiempo en la reivindicación de sus derechos- era indirectamente discriminatoria contra la mujer y no se podía aplicar, ya que era incompatible con el derecho de la Unión. ${ }^{58}$
El juez constitucional no siempre sigue las exigencias europeas. En algunos casos, es él quien asegura una protección constitucional particularmente alta, que será después retomada, in fine, a nivel europeo. Fue el caso de España, cuando el juez constitucional, en 1983, declaró inconstitucional una disposición de la ley sobre la seguridad social que excluía los hombres del acceso a una pensión de sobreviviente, esta última exclusivamente reservada a las mujeres. ${ }^{59}$ Considerando que tenía más el aspecto de una medida "paternalista" que una acción positiva, el Tribunal escogió la lógica igualitaria. ${ }^{60}$ Es interesante observar que la Corte de Justica llegara un año después a las mismas conclusiones, ${ }^{61}$ mientras que la Corte europea en un caso relativo al derecho al permiso parental para los militares iniciaba en 2012, ${ }^{62}$ expressis verbis, una lucha contra los estereotipos entre hombres y mujeres (en contra de los hombres en este caso), aunque su jurisprudencia anterior, desde 1985, mostraba voluntad de lograr la igualdad de los sexos. ${ }^{63}$

57. Tribunal constitucional español, 22 de diciembre de 2004, STC n. ${ }^{\circ}$ 253/2004 [recurso en inconstitucionalidad n. $\left.{ }^{\circ} 2045 / 1998\right]$. Tribunal constitucional español, 14 marzo 2005, n. ${ }^{\circ}$ 50/2005.

58. House of Lords (HL), [1995] 1 AC 1.

59. Tribunal constitucional español, 22 noviembre 1983, STC n. ${ }^{\circ}$ 103/1983 [Recurso en inconstitucionalidad n. ${ }^{\circ} 301 / 1982$ ]

60. Es interesante observar que en este caso el Consejo Constitucional tuvo una posición diferente, en la medida que aprobó una medida de discriminación positiva sin considerarla como una medida paternalista: Cons. const., déc. n. ${ }^{\circ}$ 2003-483 DC du 14 août 2003, Loi portant réforme des retraites, Rec., p. 430. y de justificar una desigualdad a favor de las mujeres por las cargas familiares que asumen. También de afirmar que "le corresponde al legislador tomar en cuenta las desigualdades de hecho que han perdurado en contra de las mujeres, ya que interrumpieron más que los hombres, sus actividades profesionales para asegurar la educación de sus niños”. (cons. 25). v. A. Vidal-Naquet, «Constitution et famille(s). Rapport français», AIJC, 2008, pp. 185-219.

61. CJCE, 20 mars 1984, Razzouk et Beydoun c/ Commission, aff. jtes n. ${ }^{\circ}$ C-75/82 et C-117/82.

62. Cour EDH, GC, 22 mars 2012, Konstantin Markin c/ Russie.

63. A partir de 1985, en caso Abdulaziz, la Corte afirmaba que la progresión hacia una igualdad entre los sexos constituía un objetivo importante de los Estados miembros del Consejo de Europa y que solo unas consideraciones muy fuertes podían justificar una diferencia de trato (CEDH, 28 mai 1985, Abdulaziz, Cabales et Balkandi c/ Royaume-Uni, $§ 78)$.

Criterio Jurídico Garantista. AÑo 5, No. 8. Ene.-Jun. de 2013. ISSN: 2145-3381. Fundación Universidad Autónoma de Colombia, Bogotá. 
La fuerza del principio de no-discriminación

se insertó en todas las cuestiones relacionadas con

la igualdad de los sexos y de las personas, independientemente de su edad, nacionalidad, orientación sexual, situación profesional o su situación personal (casadas, asociadas, en concubinato, solteros, etc.).

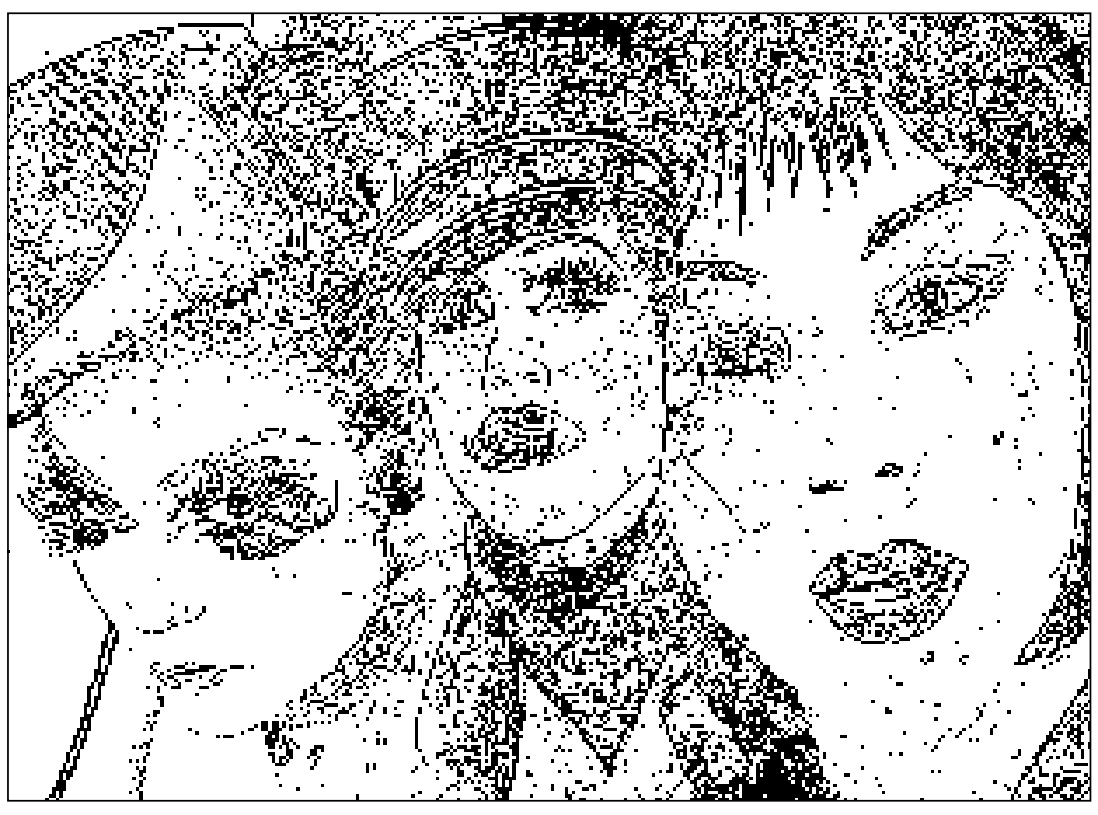

28 ¿Quién no conoce la sentencia Marcks, ${ }^{64}$ que puso fin a una distinción muy común en muchas de las legislaciones europeas entre niños legítimos y niños extramatrimoniales? Lo que probablemente desconocemos es la manera como la Corte de Arbitraje belga (actual Corte constitucional) sacó las conclusiones de esta negativa. Fundamentándose en la sentencia de condenación contra Bélgica y los artículos 10 y 11 de la Constitución, la Corte declaró inconstitucional el artículo 107 de la Ley del 31 de marzo de 1987 manteniendo, sin embargo, una diferencia de trato entre los niños en materia de sucesión. ${ }^{65}$ De hecho reiterará esta línea jurisprudencial en varios casos ulteriores, ${ }^{66}$ sin temer substituir al legislador cuando consideraba que no cumplía con la lógica igualitaria. ${ }^{67} \mathrm{La}$ Corte constitucional italiana estuvo en la misma sintonía cuando censuró, en virtud del principio de igualdad, las disposiciones del Código Civil que utilizaban el término "niños incestuosos"68 y que establecían una diferencia de trato entre niños legítimos y niños naturales. ${ }^{69}$ Hoy en día, podemos

\footnotetext{
64. CEDH, 13 juin 1979, Marckx c/ Belgique.

65. Cour d'arbitrage belge, 4 juillet 1991, Veryt c/Von Calster, n. ${ }^{\circ}$ 18/91.

66. Cour d'arbitrage belge, 1er décembre 1993, Benita M’bayo Wa Mwamba c/ Maria Winck et consorts, n. ${ }^{\circ} 83 / 93$.

67. Op. cit., pp. $218-221$.

68. Corte constitucional italiana, 20 de noviembre de 2002, n. $^{\circ} 494$, pt 5 .

69. Corte constitucional italiana, 23 de noviembre de 2000, n. ${ }^{\circ} 532$, pt 1.
} 
considerar a la luz de la jurisprudencia europea y algunas constituciones (las más recientes), que la prohibición de las diferencias de trato entre los niños es un elemento contemporáneo importante para el estatuto de los niños en derecho de la(s) familia(s).

De lo contencioso sobre la igualdad entre los sexos, las evoluciones contemporáneas mostraron también lo relacionado con la orientación sexual. Todas las jurisprudencias constitucionales evidencian la voluntad de acabar con las discriminaciones fundamentadas en la orientación sexual de los individuos. Si bien es cierto que en materia de transexualismo la jurisprudencia europea ha sido un poderoso estímulo, ${ }^{70}$ cabe señalar el carácter pionero de la jurisprudencia alemana al respecto. En una importante decisión del 11 de octubre de 1978, el Tribunal de Karlsruhe reconoció a un transexual el derecho de modificar la mención de su nuevo sexo en su registro civil, ${ }^{71}$ mientras que en Francia lo implementaron quince años después, tras una condena de la Corte europea ${ }^{72}$ que se concentró a partir de ese momento en perseguir toda forma de discriminación en contra de esta población. Por lo tanto se declararon inconstitucionales las disposiciones de la ley sobre los transexuales que reservaban la posibilidad de modificar su estado civil solo a los alemanes. El Tribunal vio una discriminación infundada e injustificada en detrimento de los extranjeros que no tenían la opción de modificar su estado civil en su país de origen. ${ }^{73}$ La jurisprudencia de la House of Lords -ahora Corte Suprema del ReinoUnido- sobre el transexualismo refleja también los efectos del proceso igualitario. El derecho al matrimonio para los transexuales fue reconocido tras haber considerado la Matrimonial Causes Act de 1973 contraria a los artículos 8 y 12 de la Convención, en el caso famoso Bellinger v. Bellinger, ${ }^{74}$ mientras que las discriminaciones en el ámbito profesional fueron lógicamente condenadas. ${ }^{75} \mathrm{La}$

70. En sus sentencias Rees del 17 de octubre de 1986 y Sheffield y Horscham c/R.U del 30 de Julio de 1998, la Corte europea concluyó que el artículo 12 de la Convención solo se refería "a los matrimonios tradicionales entre dos personas del sexo biológico diferente”. La Corte llegará a conclusiones inversas en sus sentencias I. c/ Royaume-Uni y Christine Goodwin c/ Royaume-Uni del 11 de julio de 2002, en las que usó el artículo 9 CDCUE, para justificar su cambio de orientación de su jurisprudencia, pues la Corte permitió el acceso al matrimonio a las personas que cambiaron de sexo.

71. Tribunal constitucional alemán, 11 de octubre de 1978. Decisión fundamentada en la combinación de la dignidad y el derecho al desarrollo de su personalidad.

72. CEDH, 24 janvier 1992, B. c/ France.

73. Tribunal constitucional de Alemania, 18 de julio de 2006, v. M. Fromont, «Jurisprudence constitutionnelle de la République fédérale d'Allemagne en 2006», RDP, 2007, pp. 1675-1676.

74. Los Lords decidieron que la sección 11c del Matrimonia Causes de 1973, que definía el matrimonio como una unión entre un hombre y una mujer era incompatible con los artículos 8 y 12 de la Convención ya que no tenía en cuenta la posibilidad de que los individuos pudieran cambiar de sexo después del nacimiento. V. HL, [2003] 2 AC 467.

75. Por ello, la House of Lords consideró que una mujer había sufrido discriminación por haber sido rechazado como oficial de policía, debido a su condición transexual. 
evolución jurisprudencial sobre los homosexuales es aún más sorprendente. La decisión del litigio Fitzpatrick v. Sterling Housing Association Ltd es el punto de cambio en el Reino Unido. Los Lord habían decidido que un homosexual tenía derecho a la sucesión del arrendamiento de su difunta pareja como miembro de su familia, pero no como "esposo". ${ }^{76}$ Cinco años después, una vez entrada en vigor la Human Rights Act, ${ }^{77}$ los Lord decidieron que la pareja homosexual podía ser considerada como "esposo" en virtud de la sección 3 de la Human Rights Act (Ghaidan v. GodinMendoza). En otras palabras, la exigencia de la interpretación conforma el derecho británico a la luz de la Convención Europea (in casu los artículos 8 y 14) y ha permitido a la Cámara de los Lores interpretar de manera comprensiva una disposi-

30 ción de la Rent Act de 1978, que solo permitía al "cónyuge" (en el sentido de marido y mujer) heredar el arrendamiento del difunto arrendatario.
Esta interpretación permitió evitar toda forma de discriminación entre el cónyuge sobreviviente de una pareja heterosexual $\mathrm{u}$ homosexual. ${ }^{78}$ Aunque si bien es cierto la jurisprudencia europea no pretende imponer a los Estados miembros la obligación de registrar el "matrimonio gay" en la agenda legislativa de los Estados que no lo han realizado (ver arriba), el hecho es que el principio de no-discriminación, junto con el artículo 8 permitió combatir todas las diferencias injustificadas de trato basadas en el único criterio de la orientación sexual. Ello se ve también reflejado en el ámbito de la Unión mediante el concepto de la discriminación directa. ${ }^{79}$ Esta jurisprudencia ha influenciado constantemente los litigios constitucionales, sacando a la luz casos en los que la orientación sexual no era el único criterio de restricción de un derecho, ${ }^{80}$ y otros en los que la existencia de un criterio exclusivo conllevaba a una restricción discriminatoria. ${ }^{81}$ Lo cierto es

76. HL, Fitzpatrick, [2000]1 AC 27.

77. Promulgado en noviembre de 1998 y entrado en vigor el 2 de octubre de 2000.

78. En este caso, la jurisprudencia británica fue muy audaz. El derecho francés no ha logrado aún este nivel, lo que la Corte europea aceptó, en virtud del margen nacional de apreciación: CEDH, Déc., 21 septembre 2010, Manenc c/ France). Sin embargo la jurisprudencia de la Corte de Justicia generó sin lugar a dudas una evolución de la jurisprudencia francesa al respecto (ver la referencia siguiente).

79. CJCE, Gde Ch., 1er avril 2008, Maruko, C-267/06, Rec. 2008, p. I-01757. Cuando se le preguntó si el texto que limitaba el beneficio de una pensión de reversión al «viudo» o a la «viuda» de un difunto (excluyendo el compañero de vida) del mismo sexo, infringía la prohibición de la discriminación basada en la orientación sexual, consagrada en la Directiva 2007/18, la Corte de Justicia respondió afirmativamente; siendo audaz y respetuosa de los Estados miembros. Audaz, por haber declarado que este tipo de prestación entraba en el ámbito de aplicación de dicha directiva y por haber considerado que este tipo de exclusión constituía una discriminación directa. Respetuosa del derecho de los Estados por haber remitido a la jurisdicción nacional la labor de precisión de la legislación, para saber si el texto alemán pretendía asimilar el matrimonio a la unión de vida y si la situación de cónyuges sobrevivientes era comparable a aquella de los compañeros sobrevivientes.

80. Tribunal constitucional español, 22 de diciembre de 2008, $\mathrm{STC}_{\text {n }}{ }^{\circ}$ 176/2008. En este caso, la decisión de la restricción del derecho de visita de un padre transexual, no se motivó por su transexualidad, sino por su frágil equilibrio emocional.

81. Esta sentencia es doblemente importante por lo que otorga el amparo al demandante, que afirmaba haber sido víctima de una discriminación por su orientación sexual (tras conocer su homosexualidad la compañía aérea lo licenciaba) pero también por el 
que el movimiento antidiscriminatorio ha tenido varias repercusiones sobre las formas conyugales y situaciones familiares. Hoy en día ya no se habla de la familia en singular, ya que estamos en una época de pluralismo, de acuerdo con el surgimiento de múltiples tipos de familia (reconfiguradas, monoparentales, nucleares, fragmentadas, ampliadas, legítimas, adoptivas, naturales...). ${ }^{82}$ De hecho, debido a la multitud de situaciones reveladoras de la evolución de las sociedades, la Corte europea nunca se ha aventurado a definir la "familia" y menos "la vida familiar". Por su lado, las Cortes constitucionales, con sus propias herramientas y de conformidad con la evolución de los valores, ${ }^{83}$ destacaron para enfrentar cada situación, grandes líneas jurisprudenciales. Pese a las dificultades para mantener una coherencia interna, las Cortes participaron a su manera en la transformación de la "familia" y de la "pareja".

Independientemente de la naturaleza y propósito de las diferencias de trato entre las nuevas formas conyugales (unión/asociación) y el matrimonio, así como entre las familias tradicionales y las demás estructuras familiares, las Cortes cons- titucionales en muchas ocasiones revisaron los pronunciamientos de los legisladores, y erradicaron aquellas que consideraban diferencias injustificadas de trato. En consecuencia, cuando el legislador estableció una diferencia de trato entre las parejas casadas y no casadas en materia fiscal, desfavoreciendo a las primeras, el juez constitucional la censuró por considerarla discriminatoria. Cuando la legislación española obligó a las parejas casadas a realizar una declaración conjunta en materia fiscal, el Tribunal constitucional consideró que este dispositivo constituía una violación al derecho de familia (artículo 39) y al principio de no-discriminación (artículo 14). ${ }^{84}$ Es preciso señalar que en este entonces, la tasa de imposición aplicable era mucho más alta para las parejas casadas, ya que las parejas no casadas tenían la posibilidad de hacer declaraciones separadas. Asimismo, cuando el legislador decidió favorecer las parejas casadas para la reproducción asistida, el juez consideró que la diferencia de trato se justificaba por razones objetivas. ${ }^{85}$

El proceso no-discriminatorio permitió en ciertos casos "ecualizar" modos de vida en pareja que

método de interpretación utilizado. Para concluir la existencia de una discriminación, el juez interpretó de manera comprehensiva la cláusula española sobre la igualdad (artículo 14). El Tribunal constitucional aprovechó la lista no exhaustiva de los motivos de discriminación y se remitió a los instrumentos internacionales, en particular al artículo 21 CDFUE, que prohíbe la discriminación basada en la orientación sexual.

82. Pour une analyse de «terrain» menée par un praticien, v. D. Lefeuvre, Le médiateur familial: quand et pourquoi ? Accompagner la famille dans ses conflits, Paris, Éd. Y. Michel, 2008, 192 p.

83. L. Garlicki, «La famille devant la Cour européenne des droits de l'homme», AIJC 2007, Famille et droits fondamentaux, 2008, p. 567-582; F. Sudre, «La 'construction’ par le juge européen au respect de la vie familiale», in Le droit au respect de la vie familiale au sens de la Convention européenne des droits de l'homme, op. cit. pp. 11-58.

84. Tribunal constitucional español, 20 de febrero de 1989, STC n. ${ }^{\circ} 45 / 1989$ [Auto-cuestión de inconstitucionalidad n. ${ }^{\circ} 1837 / 1988$ ].

85. Tribunal constitucional alemán, 28 de febrero de 2007 , $B V \operatorname{erf} G$, tome 117, p. 316, v. M. Fromont, «Jurisprudence constitutionnelle de la République fédérale d'Allemagne (2007)», RDP, 2008, spec. p. 1701.

Criterio Jurídico Garantista. AÑo 5, No. 8. Ene.-Jun. de 2013. ISSN: 2145-3381. Fundación Universidad Autónoma de Colombia, Bogotá. 
habían sido objeto de una diferenciación durante mucho tiempo. Así lo demuestra la sentencia emblemática del Tribunal constitucional de Karlsruhe, del 7 de julio de $2009,{ }^{86}$ pues afirmó por primera vez que el legislador no estaba autorizado para editar normas discriminatorias entre "esposos" y “compañeros", en particular en el ámbito de la remuneración de los funcionarios y de las pensiones. A pesar de que las jurisdicciones ordinarias (incluso una sección del Tribunal Constitucional) habían anteriormente privilegiado la protección del matrimonio (artículo 6.1), en este caso fue el principio de igualdad el que triunfó (artículo 3 de la Ley Fundamental).

\section{El principio de dignidad}

Denominado "Principio material” por B. Mathieu o "meta-principio" por Luc Heuschling, los calificativos son numerosos para mostrar la importancia que ha tenido este "derecho-principio" en la transformación del orden jurídico después de la
Segunda Guerra Mundial. Con este, el juez puede todo o por lo menos mucho, como lo viene confirmando la jurisprudencia alemana. ${ }^{87}$ Si existe un ámbito relativo al derecho de las personas y de la familia que ha sido particularmente invertido por las Cortes constitucionales, este es sin lugar a dudas el relativo al derecho de los extranjeros. Los litigios constitucionales al respecto demuestran una transformación de fondo, que consiste en tomar en consideración la persona humana, independientemente de su situación jurídica. ${ }^{88}$ No es que haya permitido erradicar las diferencias -inscritas en las constituciones y avaladas por la jurisprudencia europea ${ }^{89}$ - entre nacionales y extranjeros, pero sí participó en reducir, incluso en borrar en algunas circunstancias y con respecto a algunos derechos, la summa divisio entre nosotros (los nacionales) y los otros (los extranjeros). ${ }^{90}$

Si bien la Constitución española establece una desigualdad jurídica entre españoles y extranjeros (párrafo 1 del artículo 13), también afirma la importancia de recurrir a las leyes y tratados

86. Tribunal constitucional alemán, 7 de julio de 2009, v. M. Fromont, «République fédérale d’Allemagne: la jurisprudence constitutionnelle en 2009», RDP, 2010, spec. pp. 1154-1157.

87. L. Heuschling, «La dignité de l'être humain dans la jurisprudence constitutionnelle allemande», in L. Burgorgue-Larsen (dir.), La dignité saisie par les juges en Europe, Bruxelles, Bruylant, 2010, pp. 115-162.

88. En derecho internacional de los derechos humanos esta visión se desarrolló mediante la revalorización de las tesis sobre el derecho natural. Los trabajos del jurista brasilero actualmente juez a la CIJ lo demuestran: A. A. Cançado Trindade, Le droit international de la personne humaine, Paris, Pedone, 2012, p. 5-43; présentation de L. Burgorgue-Larsen (Coll. Doctrine(s)). Este movimiento se ha también insertado en el derecho positivo. Ver. La opinión de la Corte Interamericana de Derechos Humanos: Corte IDH, 17 de septiembre de 2003, Estatuto jurídico y derechos de los trabajadores migrantes ilegales, Serie A, n. ${ }^{\circ} 18$.

89. J.-P. Costa, «La Cour européenne des droits de l'homme et les étrangers», Mélanges en l’honneur de François Julien-Laferrière, Bruxelles, Bruylant, 2011 , pp. 189-202.

90. Pour un état des lieux de la question en France et son traitement par le Conseil constitutionnel, v. F. Mélin-Soucramanien, «Existet-il un droit à l'égalité de traitement des étrangers?», in E. Saulnier-Cassia, V. Tchen (dir.), Unité du droit des étrangers et égalité de traitement. Variations autour des mutations d'une police administrative, Paris, Dalloz, 2009, pp. 106-113. 
internacionales para desarrollar (a favor de los extranjeros) las "libertades públicas" (sic) consagradas en la Constitución (párrafo 2 del artículo 13). Por lo tanto, toda la jurisprudencia del Tribunal constitucional español consistirá en encontrar "el justo equilibrio" entre las evoluciones contemporáneas, que tienden a disminuir la distinción (nacional/extranjero) sin desnaturalizar su texto de referencia (bastante ambiguo). De hecho, muy temprano (1984), su jurisprudencia consistió en reconocer a los extranjeros los derechos "indispensables para la garantía de la dignidad humana" como son, el derecho a la vida, a la integridad física y el derecho a la intimidad. ${ }^{91}$ Sin embargo, hubo que esperar hasta el año 2000 para que fuera extendido el beneficio del artículo 14 de la Constitución a los extranjeros, cuando se consideró que estos eran también titulares del derecho a estar libres de discriminación basada en su raza, sexo, religión, opinión política o cualquier otra circunstancia personal o social, en la medida en que el derecho a estar libre de discriminación es indispensable para la "garantía de la dignidad humana”. ${ }^{2}$ Según la doctrina española, el avance fue importante pero no permitió el reconocimiento del derecho general a no ser discriminado por razón de nacionalidad. ${ }^{93} \mathrm{En}$ consecuencia será según el caso y dependiendo del derecho violado que el Tribunal intentará reducir la desigualdad inscrita en la Constitución. Por ejemplo, los extranjeros se benefician del derecho a la protección jurisdiccional independientemente de su estatus jurídico (en situación regular o no). En este contexto, en 2003, el Tribunal declaró inconstitucional una disposición de la ley sobre la asistencia judicial gratuita, porque el legislador había limitado este derecho a los extranjeros solicitantes de asilo y aquellos contra los que se había iniciado un proceso penal. Es preciso señalar que consideraron que "el derecho a un proceso equitativo es inherente a la dignidad humana, por lo tanto ninguna discriminación basada en la nacionalidad es aceptable". ${ }^{94}$ Esta política jurisprudencial se confirmó en la importante decisión n. ${ }^{0}$ 236/2007 ${ }^{95}$. El Tribunal declaró la inconstitucionalidad de varias disposiciones de la ley Orgánica n. ${ }^{\circ}$ 8/2000 sobre los derechos, libertades e integración social de los extranjeros en España. De hecho, el legislador había introducido una distinción bastante sutil entre la existencia de algunos derechos fundamentales (reunión, manifestación, derecho a hacer parte

91. M. Díaz Crego, «El derecho a no ser discriminado por razón de nacionalidad: un derecho de los extranjeros?», Revista española de Derecho constitucional, . $^{\circ} 89,2010$, pp. 115-135.

92. Tribunal constitucional español, 29 de mayo de 2000, STC n. ${ }^{\circ}$ 137/2000 [Recurso del amparo].

93. M. Díaz Crego, op. cit., pp. 125.

94. Tribunal constitucional español, 22 de mayo del 2003, STC n. ${ }^{\circ}$ 95/2003 [Recurso por inconstitucionalidad n. ${ }^{\circ} 1555 / 1996$ ], v. J. L. Jimena Quesada, «La justica sociale dans la jurisprudence du Tribunal constitutionnel espagnol», in L. Burgorgue-Larsen (dir.), La justice sociale saisie par les juges en Europe, Paris, Pedone,2013 (Coll. Cahiers européens, n. ${ }^{\circ}$ 4).

95. Tribunal constitucional español, STC n. ${ }^{\circ}$ 236/2007, v. M. Revenga Sánchez, «La dignité dans la jurisprudence constitutionnelle espagnole», in L. Burgorgue-Larsen (dir.), La dignité saisie par les juges en Europe, op. cit. spec. pp. 214 et s. 
de un sindicato y el derecho de huelga) y la posibilidad para los titulares de su ejercicio bajo la condición de justificar una "residencia legal" en España, lo que fue declarado inconstitucional. En Italia fue una combinación de los principios de igualdad y dignidad lo que permitió a la Corte Constitucional declarar inconstitucionales las disposiciones de una ley penal que excluía los residentes de terceros países que habían sido objeto de una condena penal, del beneficio de sanciones alternativas al encarcelamiento, únicamente por su estadía irregular sobre el territorio nacional. ${ }^{96}$

El movimiento que consiste en romper las barreras propias a la distinción nacional/extranjero se observan también en materia social. ${ }^{97}$ La jurisprudencia alemana es muy instructiva y audaz 34 al respecto, por no decir valiente, teniendo en cuenta el contexto económico actual. Articulando el principio de dignidad (artículo 1.1) con aquello del Estado social (artículo 20.1; artículo 23.1 y 28.1), el Tribunal otorga a cada individuo "un derecho constitucional subjetivo a beneficiarse de la ayuda estatal para gozar de un nivel de vida que garantice la dignidad humana”. ${ }^{98}$ De hecho, en su decisión Hartz IV du 9 février $2010,{ }^{99}$ la reforma de «racionalización» de la asistencia social, introducida por el gobierno de Gerhard Schroder, no pudo escapar a una inconstitucionalidad parcial. El Tribunal aprovechó el caso para brindar una definición extensa de los gastos incluidos en el mínimo vital, que según él, deben cubrir los gastos relativos a una estricta "supervivencia física”, pero también aquellos que garanticen una participación mínima de los individuos en la vida social. El Tribunal no niega el margen de maniobra de que dispone el legislador para determinar este mínimo vital de acuerdo con el contexto (económico, social, cultural, tecnológico, etc.), sin embargo, el poder constitucional puede intervenir en el caso de que el monto sea "manifiestamente insuficiente”. Hubiéramos podido pensar que este control mínimo del juez constitucional nunca iba a ser efectivo. Pero no, el 18 de julio de 2012, el Tribunal -retomando la jurisprudencia Hartz $I V$ - censuró las disposiciones más importantes de la Ley del 30 de junio de 1993 -que usaron el sistema de protección social para limitar la inmigración- determinando las prestaciones sociales brindadas por el Estado a los solicitantes de asilo

96. Cour constitutionnelle italienne, 5 mars 2007, n. ${ }^{\circ}$ 78, pt. 4. v. F. Martucci, «La dignité dans la jurisprudence constitutionnelle italienne», in L. Burgorgue-Larsen (dir.), La dignité saisie par les juges en Europe, op. cit. 2010, p. 194.

97. Sabemos que es la combinación del artículo 14 junto con el artículo 1 del protocolo . $^{\circ} 1$ que permite incluir los litigios sociales en el ámbito convencional. Desde la sentencia Gaygusuz c/ Austria del 31 de agosto de 1996, la Corte, luchando contra las discriminaciones basada en la nacionalidad, en el ámbito de las prestaciones sociales.

98. L. Heuschling, «Le 'méta-principe’ de l'État social dans la jurisprudence constitutionnelle allemande», in L. Burgorgue-Larsen (dir.), La justice sociale saisie par les juges en Europe, op. cit.

99. Tribunal constitucional alemán, 9 de febrero de 2010. 
y otras categorías de extranjeros, incluyendo los extranjeros en situación irregular. ${ }^{100}$ Es preciso señalar que tras esta determinación, el juez consideró que las prestaciones transferidas a este grupo de extranjeros, particularmente vulnerable, eran manifiestamente insuficientes. La Corte fustigó cualquier "dilución de la exigencia de la dignidad humana para responder a objetivos derivados de una política migratoria”. ${ }^{101} \mathrm{Su}$ firmeza no fue únicamente formal, pues decidió una revalorización de las prestaciones destinadas a los solicitantes de asilo y otros extranjeros, aplicando las normas previstas en el régimen común de asistencia social... Claramente una gran decisión.

\section{Conclusión}

A pesar de los mosaicos constitucionales europeos, de la abundancia de las jurisprudencias reveladoras de enfoques diferentes, queda claro que importantes tendencias de fondo están emergiendo y que estas posicionan la dignidad humana como un principio y un derecho que permite pro- teger todos los ámbitos de la persona humana y de cualquier discriminación.

La primera tendencia frente a estos derechos está marcada por una inclinación de los jueces a respetar la voluntad del legislador sobre asuntos en los que estiman que no son suficientemente legítimos para adaptar el derecho a la realidad fáctica, con lo cual, los jueces continúan sometidos al imperio de la ley.

La segunda tendencia posiciona el activismo de los jueces constitucionales al tomar decisiones, especialmente cuando se trata de abordar los derechos de las personas sujeto de grandes discriminaciones, especialmente por sus diferencias de edad, sexo, orientación sexual, nacionalidad o estatuto persona, etc., decisiones que se caracterizan por la audacia de los jueces en sus providencias proteccionistas, es el derecho contemporáneo que valoriza los principios de igualdad y dignidad para erradicar las discriminaciones. En este caso las cortes constucionales europeas participan con firmeza de manera innovadora en el concierto igualitario.

100. Tribunal constitucional alemán, 18 de julio de 2012

101. L. Heuschling, «Le 'méta-principe’ de l'État social...», op.cit. V. le § 121 de l’arrêt: («Die in Art.1 Abs. 1 GG garantierte Menschenwürde ist migrationspolitisch nicht zu relativieren»). 